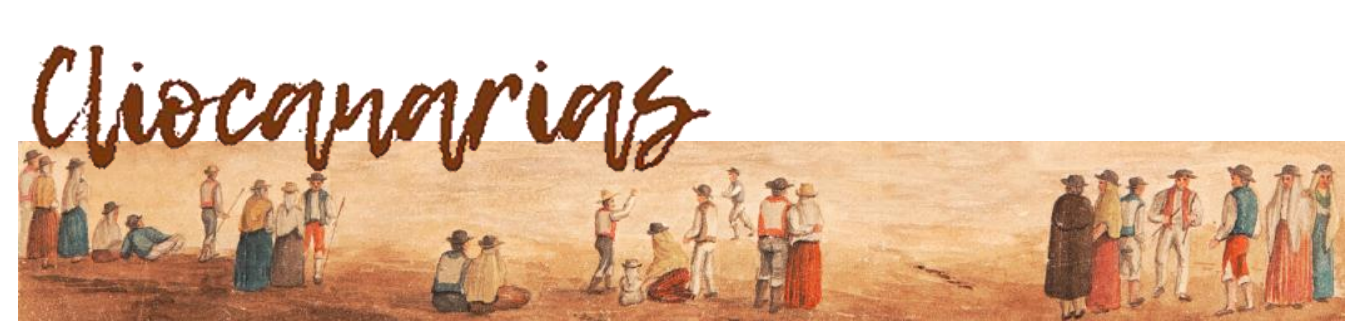

ISSN 2695-4494

https://doi.org/10.53335/cliocanarias.2021.3.14

\title{
LA DOCTRINA DE LA POTESTAS OMNINSULAR
}

THE POTESTAS OMNINSULAR DOCTRINE

Osvaldo Víctor PEREYRA*

RESUMEN: Antes de que los europeos fueran "conmocionados" por la magnitud de la extensión del espacio americano abierto por los descubrimientos, el Nuevo Mundo fue pensado — reensamblado y deconstruidodentro de los marcos constrictivos del pensamiento medieval. La primera imagen funcional que permitió "componer mentalmente" estos nuevos espacios fue la insularidad. Dicha imagen se adecuaba perfectamente a la matriz tradicional de la doctrina jurídica sustentada por el papado romano que dará por resultado las llamadas $\mathrm{Bu}$ las Alejandrinas de Partición de 1493. La potestas omninsular - desarrollada durante toda la Baja Edad Media en el Occidente europeo- constituye el basamento jurídico que otorga sentido a esta donación.

Palabras Clave: Potestas omninsular, bulas, papado, Nuevo Mundo, Colón.

ABSTRACT: Before Europeans were "shocked" by the sheer extent of American space opened up by discovery and conquest, the New World was thought - assembled and deconstructed- within the constricting frames of medieval thought. The first functional image that made it possible to "mentally compose" these new spaces was insularity. This image was perfectly suited to the traditional matrix of legal doctrine upheld by the roman papacy that will result in the socalled Alexandrian Bulls of Partition of 1493. The potestas omninsular - developed throughout the Late Middle Ages in Western Europe- constitutes the legal basis that gives meaning to this donation.

KeY WORDS: Potestas omninsular, bulls, papacy, New World, Colón.

\footnotetext{
* Profesor de Historia Moderna de la Universidad Nacional de La Plata (Buenos Aires) (UNdeMP-UC). Inst. de Investigaciones en Humanidades y Ciencias Sociales (IdIHCS/CHAyA/Facultad de Humanidades y Ciencias de la Educación). C. e: vopereyra@gmail.com. Proyecto PPID-2017: Politica, territorialidad y sociedades plurales en el Antiguo Régimen, en España y en el Río de la Plata (siglos XVI-XIX), que forma parte del Programa Interinstitucional El Mundo Atlántico en la Modernidad Temprana, dirigido por el Dr. Emir Reitano (UNLP). http:/ / pimamt.fahce.unlp.edu.ar
} 


\section{Lo insular como representación y como problema}

La creencia de haber navegado en el archipiélago asiático nunca abandonó a Colón. Aún en su lecho de muerte (el 20 de mayo de 1506), en la ciudad de Valladolid y a los 55 años, seguía profundamente convencido de haber navegado el sudeste de Asia e identificado la isla de Cipango (Japón) ${ }^{1}$, apoyándose en las referencias del mercader veneciano Marco Polo en su Libro de las maravillas - conocido en italiano como $I$ Milione ${ }^{2}$ - . Las narraciones en dicha obra son precisas y despertaban, por supuesto, la admiración y el ansia de riquezas de los europeos de la época ${ }^{3}$ :

Cipango es una isla a Levante que está a 1.500 millas apartada de la tierra en alta mar. Es una isla muy grande. Los indigenas son blancos, de buenas maneras y hermosos. Son idólatras y libres y no están bajo la señoría de nadie. Tienen oro en abundancia, pero nadie lo explota, porque no hay mercader ni extranjero que haya llegado al interior de la isla. Os contaré de un maravilloso palacio que posee el señor de la isla. Existe un gran palacio todo cubierto de oro fino, tal como nosotros cubrimos nuestras casas e iglesias de plomo, y es de un valor incalculable. Los pisos de sus salones, que son numerosos, están también cubiertos de una capa de oro fino del espesor de más de dos dedos. Todas las demás partes del palacio, salas, alféizares, todo está cuajado de oro. Es de una riqueza tan deslumbrante que no sabria exactamente cómo explicaros el efecto asombroso que produce el verlo... ${ }^{4}$.

Dicho convencimiento se trasluce también en las profusas anotaciones que el propio Colón realiza a la Geografía de Ptolomeo; la Historia Natural de Plinio; la Historia rerum ubique gestarum, de Eneas Silvio Piccolomini - el futuro papa Pío II- y en el Imago Mundi, del cardenal francés Pierre d'Ailly. Junto con ellas, otra fuente de información colombina directa fue el intercambio epistolar mantenido con el astrónomo, matemático y físico florentino Paolo del Pozzo

\footnotetext{
${ }^{1}$ En la entrada de su diario del día 21 de octubre de 1492, el propio Colón escribe: [...] Luego me partiré a rodear esta isla... y después partiré para otra isla grande mucho, que creo que debe ser Cipango, según las señas que me dan estos indios que yo traigo, a la cual ellos llaman Colba, en la cual dicen que hay naos y mareantes muchos y muy grandes, y de esta isla otra que llaman Bofio que también dicen que es muy grande. Y a las otras que son entremedio veré así de pasada, y según yo hallare recaudo de oro o especiería determinaré lo que he de hacer [...] (COLÓN, Cristóbal: Cristóbal Colón, Textos y documentos completos. Relaciones de viajes, cartas y memoriales. Edición a cargo de Consuelo Varela, Alianza editorial, Madrid, 1982).

2 En la biblioteca colombina de la catedral de Sevilla se conserva la versión en latín realizada por el fraile dominico Francesco Pipino entre los años 1310-1317. La misma conserva las cuidadosas anotaciones realizadas por el propio Cristóbal Colón.

3 Como aclara L. Arranz Márquez: El proyecto colombino es algo difícil de reconstruir y muy complicado de entender. Constituye una de las creaciones más originales y grandiosas que haya realizado el ingenio humano, ya que en él se entrecruzan realidades y sueños geográficos, mandatos de la Sagrada Escritura e imaginaciones históricas. La enjundia explicativa ha radicado en el cómo y por qué lo hizo: en cuál fue el proceso vivido por este hombre para idear, convencerse, contagiar su seguridad, ganar apoyos y triunfar, a despecho de la opinión general, y sobre todo de la opinión contraria de sabios y expertos ( ARRANZ MÁRQUEZ, Luis: Cristóbal Colón. Misterio y grandeza, Marcial Pons, Madrid, 2006, p. 157).

${ }^{4}$ POLO, Marco: Libro de las Maravillas, Anaya, Madrid, [1317] 1984, p. 133.
} 
Toscanelli (1397-T1482)5 — catedrático de la Universidad de Padua-, quien fuera también consultado por el rey portugués Alfonso V sobre la viabilidad del proyecto colombino para abrir una ruta occidental a las Indias Orientales ${ }^{6}$. Localizar la isla de Cipango era, pues, el objetivo principal que impulsaba la primera expedición —coronada por el éxito, según su propio juicio-. Así, lleno de gozo y esperanza, anota en su diario de viaje, el miércoles 24 de octubre de 1492:

[...] Esta noche a media noche levanté las anclas de la isla Isabela del cabo del Isleo, qu'es de la parte del Norte, adonde $y<0>$ estaba posado para ir a la isla de Cuba, adonde oi d'esta gente que era muy grande $y$ de gran trato y avía en ella oro y especerias y naos grandes y mercaderes, $y$ me amostró que al sudoeste iría a ella; y yo asi lo tengo, porque creo que, si es asi como por señas que me hicieron todos los indios d'estas islas y aquellos que llevo yo en los navios, porque por lengua no los entiendo, es la isla de Cipango, de que se cuentan cosas maravillosas; $y$ en las spheras que yo vi y en las pinturas de mapa mundos es ella en esta comarca?.

Animado por sus descubrimientos se atreve a rectificar al propio Marco Polo: Cipango no era en sí una isla, sino una región (el Cibao), y su descubrimiento lo situaba así frente al acceso de [...] dos tierras firmes, una la denominada del más allá - territorios dominados por el Gran Khan- y otra, la llamada del más acá, que él entendía como la [...] tierra incógnita o nuevo mundo, también ubicadas supuestamente al sudeste de Asia.

Este mundo insular se iba componiendo en la mente del Almirante como un verdadero puzle incompleto, rellenando sus piezas faltantes con elementos imaginarios y míticos. En su diario, aparecen también representadas otras realidades insulares: la isla de las mujeres $^{8}$ :

[...] habia una isla en donde no habia sino solas mujeres [...] (1lamada Matinino) las cuales se juntaban [...] durante una época del año, con fines procreadores, con los hombres de "Carib", poblada sólo por hombres $^{9}$.

\footnotetext{
${ }^{5}$ Colón sostenía que P. Toscanelli sobredimensionaba la extensión del Atlántico - lo cual es esencialmente cierto-, pero en la ecuación, la distancia que separa Europa de Asia por el occidente se encuentra determinada tanto por la extensión del océano Atlántico como por la del Pacífico (descubierto en 1513 por Vasco Núñez de Balboa), por lo que -en términos de abstracción de grados sobre la esfera terrestre- la postura de P. Toscanelli es la inferencia correcta.

${ }^{6}$ La respuesta de P. Toscanelli encuentra como inviable una vía occidental, por la extensión del océano Atlántico, que el erudito calculaba en el doble de la extensión que conocemos, lo que hacia imposible por las condiciones técnicas tal tipo de viajes sin escalas. Salvar la distancia de los $120^{\circ}$ de la esfera terrestre que requería el proyecto colombino fue para los portugueses el hecho decisivo para abandonar la arriesgada empresa. Además, la ruta africana impulsada por el príncipe Juan (futuro Juan II) se veía ya fortalecida con la construcción de la fortaleza de San Jorge de la Mina en Guinea en el año de 1482.

${ }^{7}$ COLÓN, Cristóbal: Cristóbal Colón, Textos y..., op. cit., 24 de noviembre de 1492.

8 Ibid., 6 de enero de 1493.

9 Véase ARRANZ MÁRQUEZ, Luis: Cristóbal Colón..., op. cit., p. 165.
} 
Según la descripción realizada por el propio Colón, estas islas configuraban la puerta de entrada occidental a las Indias.

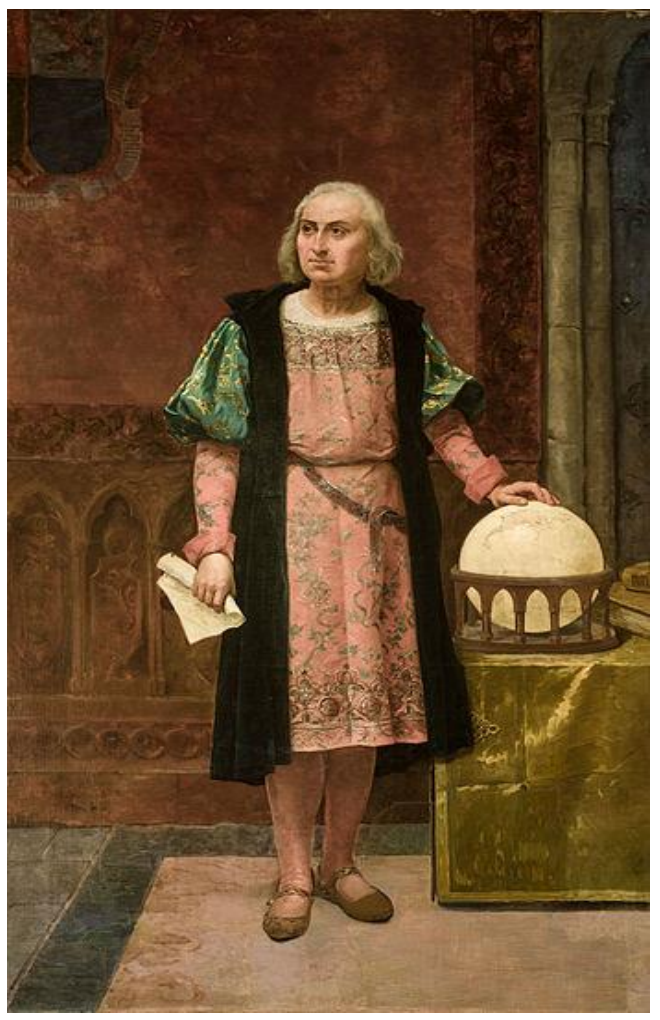

Imagen: Cristóbal Colón (Wikimedia Commons)

El tema de la insularidad es el elemento central en el ideario colombino. Aparece también alegóricamente representado en su escudo de armas otorgado por los Reyes Católicos a él y sus descendientes el 20 de mayo de $1493^{10}$. Antes de esa fecha no se conoce blasonario alguno usado por el Almirante, aunque en la concesión los reyes citan literalmente [... ] las armas vuestras que soliades tener... ${ }^{11}$, queriendo con ello significar que los monarcas dejaban abierta la posibilidad de que fuera el propio Colón quien describiera y aportara elementos heráldicos para su diseño ${ }^{12}$, De ello surge un primer boceto:

Escudo cuartelado: $\left.1 .^{\circ}\right)$ de Castilla: de gules, castillo de oro, donjonado, almenado y clarado de azur; $\left.2 .^{\circ}\right)$ de León: de plata, león de púrpura, lampasado y armado de gules; $3^{\circ}$ ) de azur, grupo de islas y campaña (Tierra Firme) de oro; $\left.4 .^{\circ}\right)$ de azur, cinco áncoras acostadas

${ }^{10}$ Los Reyes Católicos le concedieron por privilegio el poner en su escudo de armas: $1 .^{\circ}$, de sinople, un castillo de oro; $2 .^{\circ}$, de plata, un león de púrpura; $3 .^{\circ}$, en ondas de azur, unas islas de oro; y $4 .^{\circ}$, las primitivas armas propias, según dice el documento real de mayo de 1493: en el otro cuadro bajó a la mano izquierda las armas vuestras que soliades tener, las cuales armas sean conocidas por vuestras armas e de vuestros fijos e descendientes para siempre jamás.

11 Archivo General de Indias (AGI), Patronato, 9, R-1: Libro-registro de Hernán Âlvarez, f. ${ }^{\circ} 30$ vto.

12 Véase SÁNCHEZ GONZÁLEZ, Antonio: "El blasón heráldico de Colón", en VV. AA.: La heráldica en los descubrimientos y Cristóbal Colón, Sociedad Andaluza de Educación Matemática Thales, Academia Iberoamericana de La Rábida, 2013, pp. 81-92. 
de oro, puestas en sotuer. Entado en punta: de oro, banda de azur $y$ jefe de gules ${ }^{13}$.

Sin embargo, este blasonario también fue modificado por el Almirante, siendo esta tarea - según el investigador F. Martínez Llorente ${ }^{14}$ - plausiblemente solicitada al cronista Gonzalo Fernández de Oviedo ${ }^{15}$, quien añade una quinta partición donde "reaparece" - seguramente a solicitud del propio Colón- la supuesta heráldica ficcional de su linaje (banda de azur - cruzado-, jefe de gules - conquista o recuperación-y campo de oro - reconstrucción del Templo de Salomón-). Será este blasón la base que utilizarán sus descendientes, introduciéndole el mote como una bordadura externa: A Castilla y León dio nuevo mundo Colón (escudo de los duques de Veragua) o Por Castilla por León nuevo mundo halló Colón ${ }^{16}$.

\section{Occidentalis insulae y la potestas omninsular del papado}

Al mismo tiempo, son también las noticias de una realidad insular descubierta por Colón navegando al occidente - algunas islas reales (La Española, Cuba, Martinica, Guadalupe, etc.), otras imaginarias (Madanina, Antilia, Sancta y Gracia, etc.) - las que definen la necesidad de alcanzar un acuerdo político en el reparto de los espacios a explorar por las coronas de Portugal y Castilla en Tordesillas (7 de junio de 1494) ${ }^{17}$.

13 Cita en ibid., p. 86.

14 MARTÍNEZ LLORENTE, Félix: «El escudo de armas de Cristóbal Colón: estudio de un acrecentamiento heráldico", en Cristóbal Colón y el Descubrimiento del Nuevo Mundo. Actas del Congreso Internacional. V Centenario de la muerte del Almirante. Valladolid, 15 a 19 de mayo de 2006, Ayuntamiento de Valladolid, Valladolid, 2006, dos tomos, texto citado, tomo I, pp. 233-268.

15 Es debido a ello que el nuevo escudo colombino se reproduce en la obra de González Fernández de Oviedo, La Historia Natural y General de las Indias, islas y tierra firme del mar océano, Madrid, Imprenta de la Real Academia de la Historia, 1852, publicación integral. Debemos aclarar que Oviedo era reconocido en su época por un reputado "heraldista".

${ }_{16}$ Muerto ya Colón, sus hijos Diego y Hernando de Colón, motu proprio en 1502, apoyados en la publicación del Libro de los Privilegios - recopilación de los títulos otorgados por los Reyes Católicos en Santa Fe en 1492- imprimen en su portada el nuevo escudo: las armas del primer y segundo cuartel fueron modificadas para representar las de Castilla y León. Las islas del tercer cuartel fueron modificadas acompañándolas de una tierra firme en punta, con el fin de añadir las nuevas tierras continentales ya descubiertas, y en el cuarto cuartel colocaron cinco anclas para señalar su dignidad de Almirante, pero no derechas, sino tumbadas hacia la derecha.

$17 \mathrm{El}$ tratado de Tordesillas es en realidad un conjunto de dos tratados relativos a asuntos intimamente conectados que reflejan el intento de definir las esferas de poder de ambos reinos abocados a la expansión marítima. Como afirma L. Suárez Fernández: El monopolio portugués sobre las rutas de África habia venido pesando sobre las relaciones entre ambas monarquías peninsulares a lo largo del siglo XV, con alternativas entre la acritud y la amistad según soplaban los vientos de las relaciones entre los soberanos. De hecho, la posesión de las Canarias menores - y el derecho reconocido por el concilio de Basilea sobre el resto del archipiélagoaseguraba a los castellanos un punto de apoyo en el camino hacia África y América mucho tiempo antes de que esta fuera descubierta. Pero el avance sistemático de los lusitanos hacia el sur de África ponía en tela de juicio el acceso de los mercaderes a orillas del Guadalquivir a los pingües mercados del Continente negro (SUÁREZ FERNÁNDEZ, Luis: "Estudio Introductorio", en Tratado de Tordesillas, Ministerio de Educación y Ciencia, Dirección de Archivos y Bibliotecas, Madrid, 2007, cita p. 15). 
En realidad, en ese momento era desconocida la magnitud del descubrimiento colombino, y la única fuente de información de primera mano era la suministrada por el propio Almirante. Por las llamadas Capitulaciones de Santa Fe (otorgadas el 17 de abril de 1492) Colón ya había recibido la prerrogativa real para alzarse con el título de Almirante y de [...] virrey y gobernador general en las islas y tierras firmes que él descubriera:

[...] por su mano o industria se descubrieren o ganaren en las dichas mares Océanos, para durante su vida, y, después del muerto [de muerto él], a sus herederos o sucesores, de uno en otro perpetuamente, con todas aquellas preeminencias y prerrogativas pertenecientes al tal oficio ${ }^{18}$.

Se puede observar que, en las Capitulaciones se utiliza la fórmula plural islas y tierras firmes, que aparecerá replicada en la repartición territorial realizada por el papa Alejandro VI a través de la Bula Inter caetera (1493):

Alejandro obispo, y siervo de los siervos de Dios. Al queridisimo hijo en Cristo Fernando y a la queridisima hija en Cristo Isabel, ilustres reyes de Castilla, León, Aragón y Granada, salud y bendición apostólica... Habéis enviado al amado hijo Cristóbal Colón con navios y con hombres convenientemente preparados, y no sin grandes trabajos, peligros y gastos, para que a través de un mar hasta ahora no navegado buscasen diligentemente unas tierras remotas y desconocidas. Estos, navegando por el mar océano con extrema diligencia y con el auxilio divino hacia occidente, o hacia los indios, como se suele decir, encontraron ciertas islas lejanisimas y también tierras firmes que hasta ahora no habian sido encontradas por ningún otro, en las cuales vive una inmensa cantidad de gente ${ }^{19}$.

Como sugiere L. Weckmann Muñoz ${ }^{20}$ : [...] en la Edad Media, el término "terra firma" significa "masa de territorio insular", y se utilizaba para describir las costas o barras de arena mayores, en contraposición a los costas pequeñas o menores. Faltando toda posible prospección continental que implicaba tal descubrimiento, era claro que Alejandro VI aplica —en función del acuerdo entre Portugal y Castilla - los antiguos preceptos sostenidos por la Iglesia medieval desde el Papa Urbano II en el siglo XI.

El Papa, Alejandro VI, sustenta así su decisión en la propia doctrina de la potestas omninsular que tiene asiento en la interpretación -ciertamente abusiva- de la Donación de Constantino ${ }^{21}$, cuya falsificación fuera largamente

18 Capitulaciones de Santa Fe (1492). Texto integro:

http://www.historiadelnuevomundo.com/index.php/2009/11/las-capitulaciones-de-santafe-2/

19 REMESEIRO FERNÁNDEZ, Alejandro: Bula Inter Caetera de Alejandro VI (1493) y las consecuencias politico-administrativas del descubrimiento de América por parte de Colón en 1492, Galeatus, Madrid, 2004, p. 8.

20 WECKMANN MUÑOZ, Luis: Las Bulas Alejandrinas de 1493 y la teoría politica del papado medieval. Estudio de la supremacía papal sobre las islas, 1091-1493, Universidad Nacional Autónoma de México, Publicaciones del Instituto de Historia, México, 1949, p. 34.

${ }^{21}$ La Constitutum Constantini menciona la donación que el emperador Constantino habría realizado en el siglo IV, al Papa Silvestre I, de la parte occidental del Imperio romano. Tiene dos partes: por un lado, la Narratio, en el que el emperador declara la profesión de fe católica 
probada por Lorenzo Valla 22 , pero cuya última utilización politica funcional por parte del papado es la propia concesión realizada a los Reyes Católicos de las islas colombinas. En este sentido, Alejandro VI no se aparta de la tradición jurídica heredada del papado medieval.

Los antecedentes directos en la utilización de doctrina de la potestas omninsular del soberano pontífice debemos retrotraerlos a las bulas del papa Urbano II (1042-1099). Nos referimos aquí esencialmente a la Cum universae insulae (1091):

Cum universae insulae secundum instituta regalis iuris sint, constat profecto quia religiosi imperatoris Constantini privilegio in ius proprium beato Petro eiusque successoribus occidentales omnes insulae conondonatae sunt $[\ldots]^{23}$.

La bula de concesión se encuentra dirigida al abad Ambrosio, del monasterio de San Bartolomé, en el archipiélago de Lipari — situado en el mar Tirreno frente a la costa italiana-, concediendo la posesión de las islas al monasterio a cambio de un censo a la Santa Sede. Del mismo tipo, la bula Cum omnes insulae (1091):

Cum universae insulae secundum instituta regalis iuris sint, constat profecto quia religiosi imperatoris Constantini privilegio in ius proprium beato Petro eiusque successoribus occidentales omnes insulae condonatae sunt, maxime quae circa Italia oram habentur [... $]^{24}$.

\footnotetext{
y abjura del paganismo, siendo bautizado por el papa; la segunda, la llamada Donatio, por la cual toma la decisión de conceder al Trono de Pedro la primacía sobre las cuatro sedes principales de la Iglesia cristiana: Antioquía, Alejandría, Constantinopla y Jerusalén. Se entrega también el palacio imperial de Letrán y la iglesia de San Pedro en el Vaticano, el uso por el papa de los símbolos imperiales, derechos para crear patricios y cónsules, así como la soberanía sobre Roma y todo el Occidente. Véase FRIED, Johannes: "Donation of Constantine" and "Constitutum Constantini". The Misinterpretation of a Fiction and its Original Meaning, Millennium Studies in the Culture and History of the First Millennium, C. E., 3., Walter de Gruyter, Berlin-New York, 2007; también, el trabajo de ROJAS-DONAT, Luis: "El Papado bajomedieval, dueño de todas las islas. A 70 años de la teoria omni-insular de Luis Weckmann", en Teología y Vida, n. ${ }^{\circ} 61,2020$, pp. 47-72.

${ }^{22}$ Las primeras menciones de la Donatio Constantini datan del siglo IX, cuando el papa Adriano I la nombra en su correspondencia al emperador Carlomagno. Fue utilizada como documento oficial a partir de mediados del siglo XI, cuando textos de la Donación son citados por el papa León IX como argumentos para requerir a Miguel I Cerulario, patriarca ortodoxo de Constantinopla, que debía reconocerse la sujeción del Imperio bizantino a la sede papal de Roma. En general no se cuestionó la legitimidad de este hasta el siglo XV, momento en cual el humanista italiano Lorenzo Valla demostró, con el análisis filológico del documento, que se encontraba plagado de giros idiomáticos y palabras que no existían en el latín de los años finales del Imperio romano. (Véase VALLA, Lorenzo: Refutación de la Donación de Constantino, "Clásicos Latinos Medievales y Renacentistas", n. ${ }^{\circ}$ 27, edición de Antoni Biosca y Francisco Sevillano, Akal, Madrid, 2011).

${ }^{23}$ Todas las islas pertenecen al derecho público, de acuerdo con las Instituciones, y consta en el privilegio del piadoso emperador Constantino, que todas las islas occidentales han sido colocadas bajo el derecho especial de San Pedro y de sus sucesores [...] (Citado por ROJAS-DONAT, Luis: "El Papado bajomedieval...", art. cit., p. 55.

${ }^{24}$ Todas las islas pertenecen al derecho público, de acuerdo con los estatutos legales, y consta también que por la generosidad y el privilegio del piadoso emperador Constantino han sido colocadas bajo el derecho especial de San Pedro y de sus vicarios [...]. Ibid.
} 
También, la bula de concesión de la isla de Córcega a la República de Pisa, pagando a la Sede Romana un censo perpetuo. La lista de ejemplos se extiende: según lo formuló en su época L. Weckmann, la bula Laudabiliter (1155) por la cual el Papa Adriano IV concedió a Enrique II de Inglaterra la isla de Irlanda, así como, desde el siglo XII, también Escandinavia -considerada entonces como isla-y otras situaciones insulares en el Mediterráneo ${ }^{25}$.

Habria también paralelismos extremos en la doctrina medieval que cimientan en este sentido la potestas universal. Por ejemplo, lo sugerido por E. H. Kantorowicz, ${ }^{26}$ en cuanto al desarrollo de la idea de la continuidad de la sucesión real. Dicha formulación termina con el principio papal de que entre la muerte de un rey y la consagración del otro existe el llamado "interregno de Cristo", tiempo durante el cual su vicario en la Tierra puede intervenir en los reinos. Esta intervención fue obstaculizada por el establecimiento del principio de la continuidad dinástica, que impedía así la intervención papal. Por extensión, estas islas recién descubiertas pueden ser tomadas también como monarquías acéfalas y otorgadas, en virtud de la potestas omninsular del vicario de Cristo en la Tierra, a príncipe cristiano.

\section{La potestas omninsular en el contexto de la expansión atlántica hacia el siglo xv}

Si bien es cierto que podemos rastrear la utilización de esta doctrina omninsular desde el siglo XI en adelante ${ }^{27}$, aquello que nos interesa en este momento es señalar cómo funciona aquella en término de la empresa de expansión marítima de los reinos ibéricos. En este sentido, los antecedentes inmediatos directos a las bulas alejandrinas de partición deben buscarse en las donaciones realizadas por los papas a los reinos de Castilla y de Portugal desde principios del siglo XV:

- Apostolatus officium (1403) y Romanus pontifex (1404) se elaboran teniendo en cuenta la situación en las islas Canarias por el papa Benedicto XIII y se realizan bajo el espíritu de cruzada, sobre población considerada infidelis (infieles), entendiendo desde un primer momento que estos isleños no eran musulmanes, pero sí paganos. Por la primera de estas bulas el papa establece que tras: [...] la conquista de Lanzarote concede gracias espirituales (indulgencias) a todos los que trabajaren en su defensa, en la conquista de las otras islas y en la conversión de los indigenas y con limosnas para dichos fines (con donativos no inferiores a la cantidad necesaria para el mantenimiento de un hombre de armas durante seis meses) ${ }^{28}$. En cambio, la Romanus pontifex erige el primer obispado en las Canarias, el cual tendría su

25 Véase WECKMANN MUÑOZ, Luis: Las Bulas Alejandrinas de 1493 y la teoría politica del papado medieval. Estudio de la supremacía papal sobre las islas, 1091-1493, Universidad Nacional Autónoma de México, Publicaciones del Instituto de Historia, México, 1949.

26 Véase KANTOROWICZ, Ernst: Los dos cuerpos del rey. Un estudio de teología politica medieva, Madrid, Akal. Nos referimos específicamente al capítulo VII, "El rey nunca muere", reimpresión de 2018, pp. 317-440.

27 Una sintesis del problema en URIBE RUEDA, Álvaro: Bizancio, el dique iluminado, ediciones LAVP, New York, 2019.

28 RUMEU DE ARMAS, Antonio: "Colección de Bulas y Letras expedidas por los pontífices Benedicto XIII, Martín V, Eugenio IV y Nicolás V, promoviendo la primera cristianización de 
sede en la ciudad fortaleza de Rubicón (en la isla de Lanzarote) en la catedral de la diócesis rubicense de la iglesia de San Marcial. Se entendia que el poder del papa se extiende [...] cuncta orbis climata omniumque nationus degentium qualitates, es decir, sobre [...] todas las regiones del mundo, todas las naciones y cualidades de vida ${ }^{29}$.

- Rex regum (1418). Conquistada Ceuta por los portugueses en el año de 1415, Juan I de Portugal solicita a Martín V una bula de cruzada para el occidente africano, concediendo indulgencia plenaria a todos aquellos que participen en la empresa. Fue reafirmada con la Rex regum de 1436.

- Etsi cunctis (1434), por la cual el papa Eugenio IV exime [...] a los conversos presentes y futuros de las islas Canarias del pago de diezmos y primi$\operatorname{cias}^{30}$ frente a los señores de la isla; y la bula Regimine grengis (1434), protegiendo a los indígenas convertidos de Canarias de la "esclavización" bajo pena de excomunión.

- Rex regum (1436) es esencialmente una réplica de la de 1418, posteriormente reafirmada con la Rex regum de 1443. ¿Qué había cambiado para los portugueses para insistir con estas reafirmaciones de derechos frente al papado? Simplemente, el hecho de que en 1434 Gil Eanes alcanza el cabo Bojador. Tocado ese punto, el tornaviaje vuelve geoestratégicamente importante la posición de las islas Canarias para el reabastecimiento. Sin embargo, si bien la justificación de cruzada era fácilmente aplicable contra los musulmanes marroquíes y los mauritanos de la costa africana, en Canarias la población indigena era distinta. Además, también estaba la desatada contienda con el reino de Castilla y sus derechos sobre las islas.

- Romanus pontifex (1436). La sede romana se había convertido ahora en escenario diplomático de las disputas por los derechos de expansión de Portugal y Castilla por las islas Canarias. Sin embargo, para nuestro problema es importante recalcar cómo pondera esta bula de delegación de soberanía papal. El papa actúa en virtud de un poder confiado a él: [...] de omnipotentis Dei misericordia et beatorum Petri et Pauli apostolorum eius auctoritate confisi et illa quam nobis Deus licet immeritis ligandi atque solvendi contulit potestate [...] cuius est orbis terre et plenitudo eius (con la finalidad) ad propagationem christiani nominis $[. . .]^{31}$ componiendo, al mismo tiempo, una salvedad: que [...] no pertenecieran a otros principes cristianos.

las Islas Canarias. La Diócesis del Rubicón”, en Anuario de Estudios Atlánticos, n. ${ }^{\circ}$ 52, 2006, pp. 109-134.

${ }_{29}$ Véase CASTAÑEDA DELGADO, Paulino: La Teocracia Pontifical en las controversias sobre el Nuevo Mundo, México, Universidad Nacional de México, Serie C, Estudios Históricos, n. ${ }^{\circ}$ 59, 1996, p. 284.

30 RUMEU DE ARMAS, Antonio: "Colección de Bulas...", art. cit., p. 125.

31 [...] Por la misericordia del Dios todopoderoso y por la autoridad de sus bienaventurados apóstoles Pedro y Pablo, el poder de atar y desatar nos fue conferido, aún sin tener los méritos [...] que es la Tierra y todo (con la finalidad) de difundir el nombre de Cristo [...]: en MARTINS DA SILVA MARQUES, João: Descobrimentos portugueses. Documentos para a sua historia, Instituto de Alta Cultura, Lisboa, 1944, vol. I (1415-1460), pp. 368-369. 
- Preclaris tue devotionis (1437). Por ella el papa autoriza a los portugueses a comerciar con infieles usando la siguiente expresión: Nos [...] apostolica auctoritate tenorepresentium indulgemus $[\ldots]^{32}$.

El otorgamiento de estas concesiones al rey de Portugal solo demuestra la efectividad, hasta esos momentos, de la diplomacia lusa en la Corte romana. Con la finalidad de lograr la revocación de la concesión de derechos a Portugal sobre las islas Canarias, el rey Juan II de Castilla (1406-1454) encarga al obispo de Burgos, Alonso de Cartagena —quien habia desempeñado varias embajadas en Portugal - trasladarse a la Curia romana y defender alli los derechos castellanos sobre las islas. Escribe las llamadas Alegaciones sobre la conquista de las Islas Canarias, de 1436. En la tercera parte de las Alegaciones, encontramos el conjunto de argumentaciones que sostienen los derechos del rey de Castilla sobre dichas islas:

1) Tingitana (Mauretania Tingitana = antigua provincia romana noroccidental de África) pertenece a Castilla y León; ahora bien, las Canarias son islas de Tingitana, luego son parte de Castilla [...], 2) el rey Enrique hizo ocupar [...] la isla de Lanzarote con intención de recuperar todas [...]; la consecuencia no puede ser más que una: las islas Canarias son del rey de Castilla y León, y nadie puede ocuparlas sin expresa licencia o benigna tolerancia del rey [... $]^{33}$.

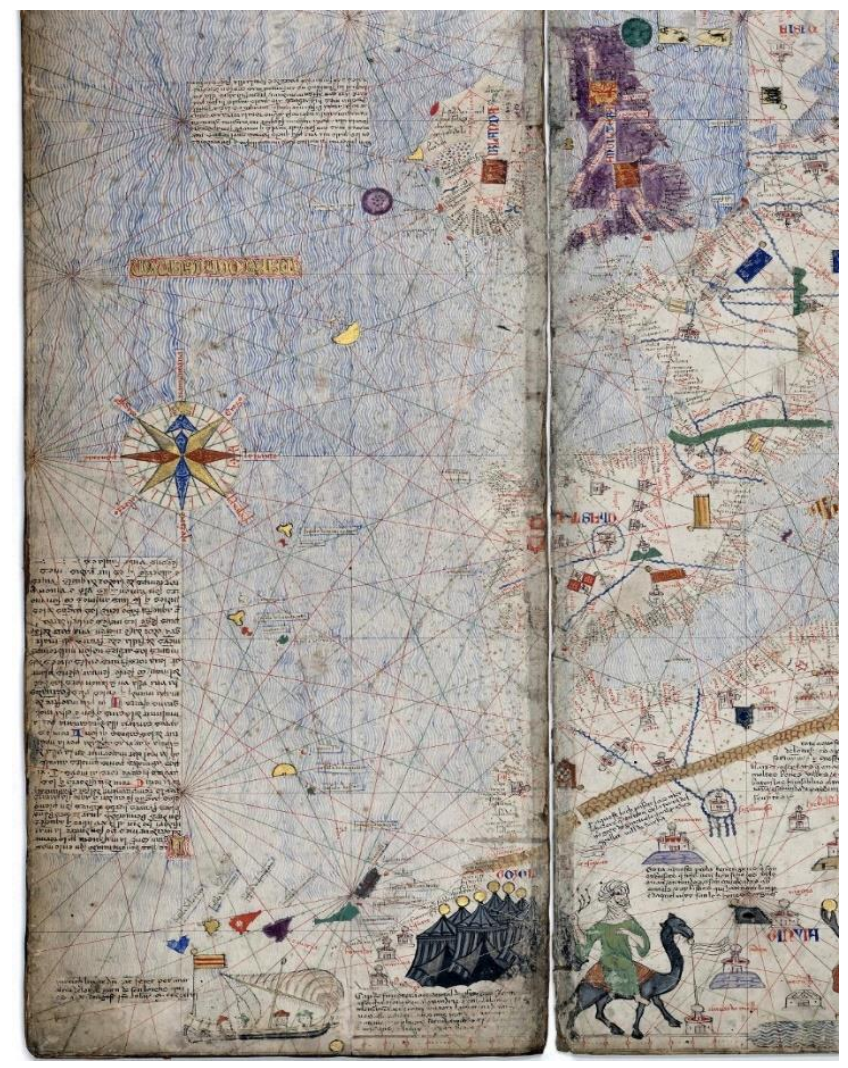

Imagen: Las islas Canarias en una reproducción parcial del mapa de los Cresques (s. XIV) (Wikimedia Commons)

${ }^{32}$ Nosotros [...] al tenor de las circunstancias actuales, por autoridad apostólica, condescendemos [...]. Ibid., p. 380.

${ }^{33}$ Véase CASTAÑEDA DELGADO, Paulino: La Teocracia..., op. cit., p. 289. 
La puerta estaba entreabierta. El otorgamiento de la Bula Romanus pontifex (1436) en su concesión conllevaba la fórmula: [...] no pertenecieran a otros príncipes cristianos. Hacia 1554-1555 asistimos a un cambio en los escenarios en que se desenvolvía la agria disputa de derechos entre Portugal y Castilla. Se habían desarrollado plenamente los horizontes y la dirección de la expansión. Para los intereses portugueses se volvió central consolidar la empresa africana, entendiendo con ello la exclusividad sobre Guinea. Se daban las condiciones para cerrar un acuerdo de partes con el inmediato competidor caste1lano. El reconocimiento de la exclusividad de derechos de los portugueses sobre Guinea por parte de Castilla permitiria, como contrapartida, el correspondiente reconocimiento de los derechos castellanos en Canarias

Paralelamente, el escenario continental europeo también cambiaba. La caída de Constantinopla (1453), la situación en los Balcanes y la expansión de los turcos hacian que el papado mirara con interés cualquier empresa de cruzada contra ellos y, al mismo tiempo, se esforzara en sostener la paz entre los reinos cristianos. Dos bulas, otorgadas por el Papa Nicolas V, son fundamentales durante este período en relación con nuestro tema:

- Dum diversas (1452). Al estilo de bula de cruzada se concede autorización a Alfonso V para conquistar y someter a los sarracenos, paganos y otros infieles enemigos de Cristo, apoderarse de sus territorios y bienes, someterlos a perpetua servidumbre y trasmitirlos [...] a sus sucesores [...]. Asimismo concede indulgencia plenaria - plenariam remissionen - al rey y a todos los que le acompañaren cada vez que hiciera guerra a los infieles $[\ldots]^{34}$. Los moros presionaban el enclave portugués de Ceuta y se juzgaba fundamental ayudar a mantener las plazas africanas.

- Romanus pontifex (1454). Si Dum diversas es una bula de cruzada "abierta" - no entiende restricción espacial alguna-, esta bula declara que dicha autorización se aplica a Ceuta y a todas las adquisiciones pasadas y futuras sobre infieles [...], y el derecho a conquistar hacia el sur de los cabos Bojador y Num, han sido y son derecho propiedad exclusiva del Rey de Portugal $[. . .]^{35}$. Podemos decir también que en ninguna de estas dos bulas aparece el tema de las islas Canarias, y en esta última se coincide plenamente con el interés de Portugal por legitimar el espacio africano como frente de expansión $^{36}$. De esta manera, el papa tampoco entraba en contradicción con la posición castellana respecto a los derechos sobre el archipiélago canario, conformando así a ambos por igual.

La bula Inter caetera (1456), dictada en el transcurso del breve pontificado de Calixto III, confirma lo postulado en la Romanus pontifex. La situación de la cristiandad estaba muy comprometida frente al avance de los turcos, pues la flota del sultán amenazaba con el control del Mediterráneo. El papa, de avanzada edad, era también considerado un hábil diplomático. Su prioridad

\footnotetext{
34 Ibid., p. 298.

35 Ibid., p. 300.

${ }^{36}$ La bula animaba a los portugueses a continuar y a hacer el mar navegable hasta los "indios" (en realidad, los indios conocidos como cristianos de Santo Tomé) que, según se decía, adoran el nombre de Cristo, de manera que pudiera comunicarse con ellos y moverlos en ayuda de los cristianos contra los sarracenos.
} 
fue consolidar una "gran armada" de todos los reinos cristianos para enfrentar la amenaza. Debía por ello contar con Portugal y su flota. La Inter caetera se perfila dentro de esas coordenadas: [reafirma] la jurisdicción espiritual sobre todos los territorios conquistados o a conquistar, colocados ya bajo la soberanía de Portugal por Nicolas V desde los cabos de Num y Bojador, pasando por Guinea, y más allá $[. . .]^{37}$.

La muerte del papa ( $\$ 1458)$ y del principe de Portugal, don Enrique "el Navegante" ( $\$ 1460)$ son eventos para señalar, pero en realidad no cambian el eje de la proyección territorial portuguesa. La asunción al trono de Alfonso V permite continuar con la expansión africana iniciada por su predecesor. Así lo confirma la conquista de Marruecos, de Arcila, Tánger, etc. En tanto, en la península, el fin del conflicto entre Portugal y Castilla en el marco de la guerra de Sucesión al trono portugués, a través del Tratado de Alcaçovas (1479), permite alcanzar los decisivos compromisos entre las partes. Lo que nos interesa aquí, precisamente, es señalar las delimitaciones alcanzadas en torno a los espacios de expansión. Sintetizando: 1) Los Reyes Católicos reconocen a la Corona de Portugal el señorío sobre el reino de Fez (zona noroccidental africana), archipiélago de las Azores y Madeira, así como sus derechos sobre Guinea; 2) por el lado de Portugal, se reconoce a Castilla la posesión de las islas Canarias: a saber, Lançarote, Palma, Fuerteventura, La Gomera, el Fierro, la Graciosa, la Gran Canaria y Tenerife [...] e todas las otras yslas de Canaria ganadas e por ganar $[. . .]^{38}$. La finalidad es clara: reconocer señorío y preeminencia sobre cada uno de estos reinos en los distintos espacios de expansión. No hay una proyección ni proyección sobre "la mar Océano". Tampoco debería haberlas. Es claro que el Tratado de Alcaçovas tiene como finalidad ser un tratado de paz, y por ello, solo toca tangencialmente el reconocimiento mutuo de señorio sobre espacios extrapeninsulares. Al obturar el conflicto en la península, ambas monarquías "guardan sus espaldas", pudiendo así continuar sus correspondientes acciones de cruzada: por un lado, Portugal en la costa de África; por el otro, Castilla y su lucha contra el último bastión de presencia musulmana en la península, el reino nazari de Granada.

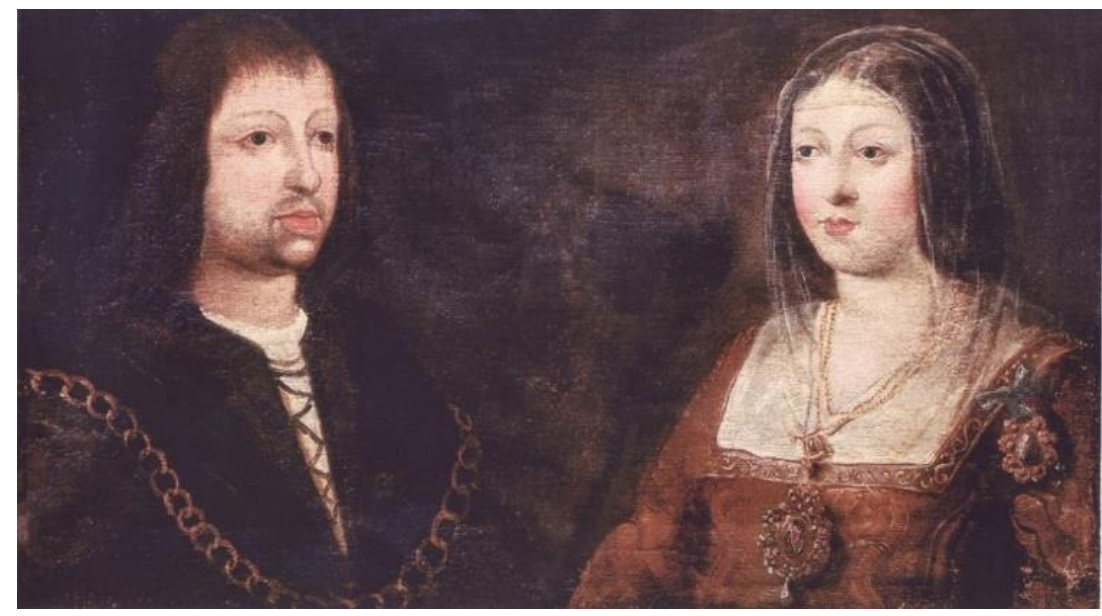

Imagen: Los Reyes Católicos (Wikimedia Commons)

37 Véase CASTAÑEDA DELGADO, Paulino: La Teocracia... , op. cit., p. 305.

38 Ibid. p. 309. 
La bula Aeterni regis (1481), otorgada por el papa Sixto IV, sintetiza las disposiciones otorgadas en Romanus pontifex, Inter caetera y el propio Tratado de Alcaçovas, según el pedido de Portugal. Se agrega también al texto la indulgencia plenaria para todos aquellos que muriesen en la construcción de las fortificaciones en la Costa del Oro en África occidental (actual Ghana): [...] in castello apud Minam in partibus Ethiopie constructo [... $]^{39}$.

Mediante la bula Orthodoxe fidei (1486) el papa Inocencio VIII concedía a los Reyes Católicos el regio patronato en las islas Canarias y en Granada: Innocentius episcopus [...] orthodoxae fidei propagationem [...] tales sunt, carissimus in Christo filius noster (Fernando e Isabel) expugnationis infidelium insularum Canariae prosequi et continuare curarunt, sed etiam regnun Granatae ante eorum oculos $[\ldots]^{40}$. La lucha contra los infieles es nada más que el titulo o motivo que sostiene la concesión por parte del papa de estos derechos amplios. La parte dispositiva concede el derecho de patronato: plenum ius patronatus [...] in cisdem locis regni Granatae et insularum Canariae [... $]^{41}$.

Con estos antecedentes, el año 1492

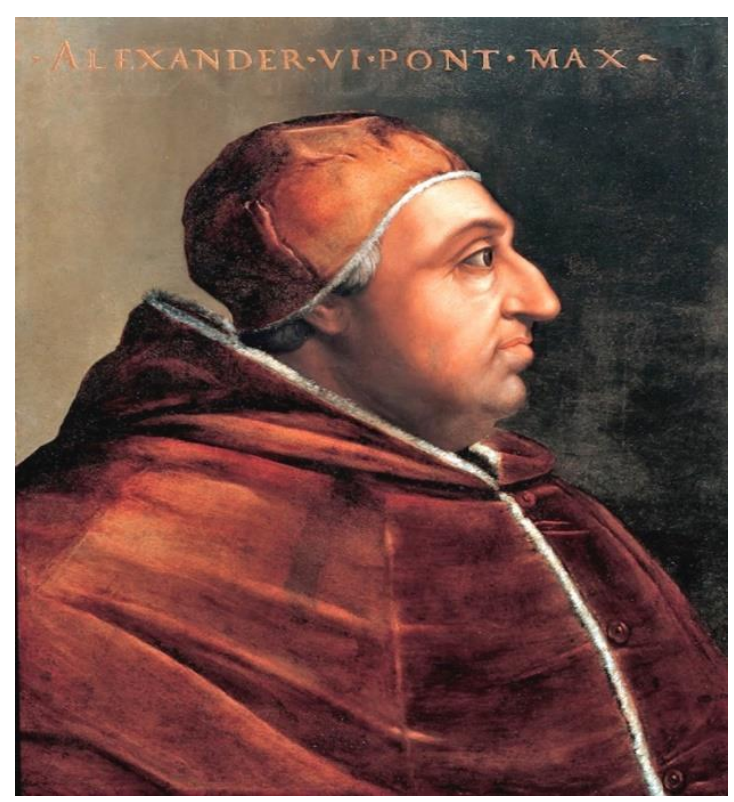

Imagen: Papa Alejandro VI (Wikimedia Commons) nos sitúa en una nueva "bisagra" del problema. El descubrimiento de las islas de Colón —navegando hacia occidente- induce de inmediato a los Reyes Católicos a considerar insuficiente por sí solo el título de descubrimiento y ocupación, buscando así nuevas concesiones por parte del papado romano ${ }^{42}$. El resultado de tales diligencias diplomáticas son las llamadas Bulas Alejandrinas, otorgadas por el Papa Alejandro VI.

\footnotetext{
39 Ibid., p. 316.

40 Inocencio obispo, [...] para la difusión de la verdadera fe [...] a los tan amados los hijos de Cristo (Fernando e Isabel) la toma de las islas Canarias de los infieles y los mueven a seguir dando pasos, y también el Reino de Granada ante sus ojos [...]. HERA, Alberto de la: "El regio patronato de Granada y las Canarias", en Anuario de Historia del Derecho Español, Tomo LXXXVII, 1957-58, pp. 5-16, cita en p. 5.

41 Ibidem.

42 El descubrimiento de las primeras islas del Caribe durante los viajes de Cristóbal Colón y las medidas tomadas por los Reyes Católicos como consecuencia de este cambiaron dramáticamente la situación. En su intento por asegurar los derechos exclusivos sobre los nuevos territorios una vez retornado Colón, en marzo de 1493, los Reyes Católicos captaron el apoyo del Papa Alejandro VI. A los pocos meses, el Papa ya habia concedido un total de cinco bulas que otorgaban a los españoles una serie de derechos sobre las Indias (las llamadas bulas alejandrinas) (DUVE, Thomas: "El tratado de Tordesillas: ‘¿Una revolución espacial?' Cosmografia, prácticas jurídicas e Historia del Derecho Internacional Público", en Revista de Historia del Derecho, n. ${ }^{\circ}$ 54, Instituto de Investigaciones de Historia del Derecho-Buenos Aires, julio-diciembre de 2017, pp. 77-107, cita en p. 83).
} 
Son un total de cinco bulas, otorgadas durante el transcurso del año 1493, las cuales deben ser vistas como complementarias entre sí y funcionando dentro del conjunto de antecedentes que hemos estado describiendo:

- La primera, Inter caetera (1493) (bula de donación), hace donación a los Reyes Católicos de las islas y tierras firmes que se descubrieran navegando hacia occidente, siempre y cuando no pertenecieran a otros "príncipes cristianos", estableciendo asi el mismo formato de otorgamiento que hemos visto con el reino de Portugal.

- Eximie devotionis (1493) (Bula de privilegios), otorga a los Reyes Católicos los mismos privilegios y derechos otorgados en su oportunidad a Portugal.

- Segunda bula Inter caetera (1493), que es la primera en señalar una línea divisoria de espacios, fijada a cien (100) leguas (trazada imaginaria de norte a sur) situada al oeste de las islas Azores y Cabo Verde. Esto sí comprende una novedad en las formulaciones tradicionales, pero hay que recordar también que esta fórmula aparece ya consignada, un mes antes, en la confirmación a las Capitulaciones de Santa Fe (1492) (fechada el 28 de mayo de 1493), que concedian a Colón el título de Almirante de la Mar Océano: [...] que es nuestro, que comienza por una raya o linea que nos habemos fecho marcar que pasa desde las islas de los Azores a las islas de Cabo Verde, de septentrión en austro, de polo a polo; por manera, que todo lo que es allende de la dicha linea al Occidente, es nuestro e nos pertenece ${ }^{43}$. Es posible así que fuera a instancias de los conocimientos prácticos del propio Colón y de sus observaciones que el papa aceptara la idea del trazado de esta línea imaginaria.

- Dudum siquidem (1493) (Bula de ampliación), que se asienta en la visión de Colón de que había llegado a las Indias Orientales y frente a las pretensiones portuguesas de demarcación de espacios a través de la línea astronómica del paralelo que cruzara sobre Canarias, separando así dos espacialidades: norte castellano, sur portugués. El papado sostiene su posición involucrando así a las islas y tierras firmes descubiertas y por descubrir navegando hacia occidente bajo la consabida fórmula: [...] que no estuviesen ocupadas de hecho por otro príncipe cristiano ${ }^{44}$. Debemos tener en cuenta que, a esas alturas, la única información de primera mano sobre este espacio totalmente desconocido para el europeo de la época era las referencias realizadas por el propio Almirante.

- Piis fidelium (1493) simplemente concedió a fray Bernardo Boil amplias facultades espirituales, a quien los Reyes Católicos luego enviaron a encabezar la evangelización en el Nuevo Mundo.

43 FERNÁNDEZ DE NAVARRETE, Martín: Colección de los viajes y descubrimientos que hicieron por mar los españoles desde fines del siglo XV, (1825-1837, reimpr. 1945), vol. II, pp. 7379. Citado por DUVE, Thomas: "El tratado de Tordesillas ...", art. cit., p. 85.

${ }^{44}$ Ibid., p. 322. 
Imagen: Reparto establecido en el Tratado de Tordesillas (1494)

(Wikimedia Commons)

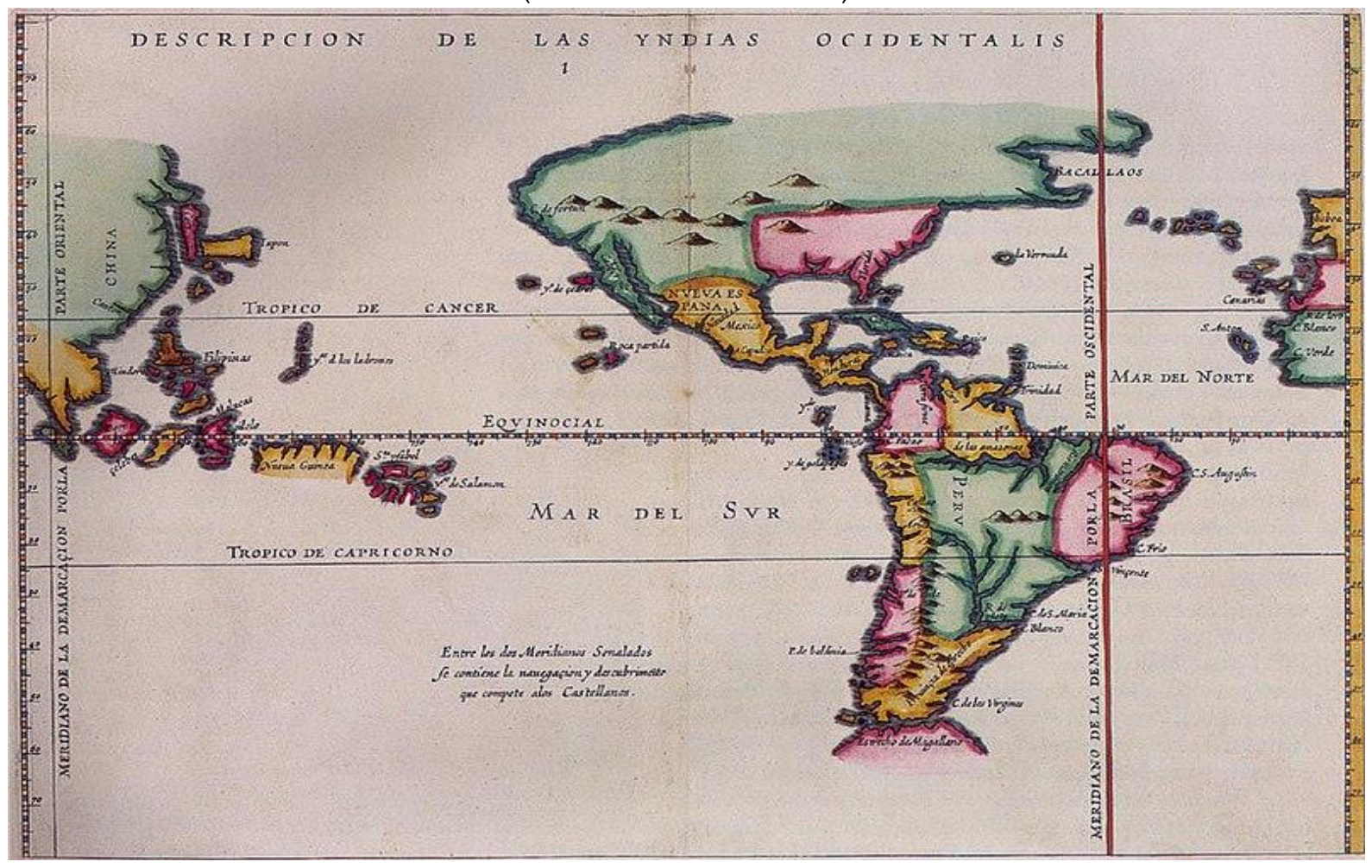

Vistas asi en conjunto, estas intervenciones papales que abarcan un período de noventa años, desde la Apostolatus officium (1403) hasta las llamadas Bulas Alejandrinas de partición (1493), todas se comportan como antecedentes necesarios que nos remiten al año 1494 y las Capitulaciones de Tordesillas. Suponen un auténtico compromiso de partes entre las dos monarquías ibéricas, donde los representantes del rey Juan II (Portugal) y los Reyes Católicos (Castilla y Aragón) establecieron un reparto de las zonas de navegación y conquista del océano Atlántico y del Nuevo Mundo mediante el trazado de una línea situada a 370 leguas al oeste de las islas Azores para evitar futuros conflictos de intereses.

Debemos tener en consideración, en primer lugar, que el centro del acuerdo es exclusivamente el Atlántico (la mar Océano), pues otros mares aún no habian sido descubiertos. En segundo lugar, que en la decisión castellana de aceptar al oeste la linea divisoria pesara fuertemente la necesidad de mantener la paz entre los reinos peninsulares más allá de cualquier otra especulación. Sea como fuere, lo cierto es que los Reyes Católicos acceden a sumar otras 270 leguas a la fórmula original propuesta. Al mismo tiempo, se simplifica la delimitación espacial de aquella, asumiendo ahora un solo punto de partida desde donde establecer las respectivas demarcaciones: las islas Azores. Este hecho abriría otro conjunto de problemas en función de la prospectiva continental americana que - para la fecha de redacción - aún era totalmente desconocida para los participantes. 


\section{De la potestas omninsular en perspectiva}

Como vemos, una serie de factores y condicionantes confluyen casualmente en el transcurso del siglo XV, y permiten componer el problema en perspectiva. Hacia el siglo XVI estos marcos habrán cambiado dramáticamente los significados previamente sostenidos:

1) En primer lugar, hacia el siglo XV el lugar del papa como cabeza de la cristiandad occidental y la preeminencia de la Iglesia de Roma ${ }^{45}$ sobre la cristiandad occidental era aún, en cierta manera, indiscutida ${ }^{46}$. Las teorias teocráticas eran moneda corriente entre canonistas y juristas de la época, a pesar de que los postulados del movimiento conciliar de reforma de la Iglesia reaparecieran permanentemente ${ }^{47}$, y que las teorias cesaristas - cuya expresión más extrema la encontraremos en la pluma de Marsilio de Padua-48 fueran ganando cada vez más terreno en su puja contra el universalismo papal ${ }^{49}$. Resulta paradójico que estas bulas de cruzada (otorgadas

\footnotetext{
45 Según la cultura jurídica imperante en el siglo xv, por la cual el papa era reconocido como la cabeza de la congregatio fidelium ecclesia y sobre el cual no existía superior alguno, este podía juzgar por encima de todo y de todos -aún por encima del poder temporal de los príncipes y del emperador - bajo la fórmula, ya consagrada: [...] sedes apostolica omnes iudicat et a nemine iudicatur (GIERKE, O. Von: Teorias politicas de la Edad Media, Centro de Estudios Constitucionales, Madrid, 1995, p. 169).

46 Debemos tener en cuenta que hacia finales del siglo XV - momento en el cual esbozamos nuestro estudio- podemos observar tres grandes corrientes doctrinales compitiendo en la interpretación de la relación entre papado e imperio. Sintetizando la cuestión: por un lado, tendriamos las llamadas teocráticas (subsumen lo natural a lo espiritual), el papa sería - por delegación de Cristo- señor sobre fieles e infieles, y los poderes temporales estarían subordinados al poder espiritual. Por el otro lado, en su extremo opuesto, la cesarista, que defendía el origen natural del poder civil, principio de toda sociedad, negando así la sumisión incondicional del emperador al papado. Por último, y en el medio de estas dos posturas extremas, se encontrarian las doctrinas que sostenian el poder indirecto. Basadas en los postulados del tomismo, entendía al imperio y al papado como dos poderes surgidos del orden natural y queridos por Dios donde el segundo actuaría sobre el primero como orden moral y dirección espiritual. Es claro que esta situación cambia dramáticamente en el siglo XVI, cuando la matriz espiritual europea es fracturada por la Reforma. La posibilidad de pensar la significación que tiene la potestas omninsular sostenida por el papado romano en la formulación de estas bulas de partición solo puede ser entendida si comprendemos que en estos años el poder del papa para realizar este tipo de donación extraterritorial no estaba en entredicho, y que su autoridad era aceptada por el conjunto de las partes involucradas.

47 Véase sobre el problema de los aspectos generales del movimiento conciliar en el siglo XV, el trabajo clásico de SABINE, George H.: Historia de la teoría política, Fondo de Cultura Económica, México, ([1937] 1996). Especialmente, en segunda parte, capítulo XVII, "La teoría conciliar del gobierno de la Iglesia", pp. 251-264.

48 Véase sobre esta problemática de las teorías cesaristas y la figura de Marsilio de Padua en: BAYONA, Bernardo y Pedro ROCHE: Sobre el poder del Imperio y del Papa, Biblioteca Nueva, Madrid, 2005; BERTELLONI, Francisco: "Constitutum Constantini` y 'Romgedanke'. La donación constantiniana en el pensamiento de tres defensores del derecho imperial de Roma: Dante, Marsilio de Padua y Guillermo de Ockham", (2. ${ }^{a}$ parte), Patrística et Mediaevalia, n. ${ }^{\circ}$ 4-5, 1984, pp. 67-99.

${ }^{49}$ Según la tesis de ULMANN, Walter: A short history of the papacy in the Middle Ages, Methuen and Co. Ltd., Londres, 1972, pp. 331-332: No fue la Reforma la que puso su sello en el papado medieval, sino el propio papado en el siglo XV, cuando la institución se retiró a un segundo plano y su lugar fue ocupado por una sucesión de individuos que no eran más que ricos italianos ennoblecidos y cuya cualificación para el desempeño de los cargos podía ser cuestionada bajo cualquier prisma. Citado por PRODI, Paolo: El Soberano Pontífice. Un cuerpo y dos almas: la
} 
a Portugal) y las Alejandrinas de partición (otorgadas a los Reyes Católicos) deban ser consideradas como la última representación jurídica del poder temporal universal del papado romano ${ }^{50}$. Mientras la unidad del orbe cristiano europeo no fuera puesta en entredicho con las convulsiones religiosas provocadas por la Reforma, dicha potestad y derechos generados por la concesión de los pontífices no encontraron una oposición significativa. Debemos también tener presente que en aquel momento ni castellanos, ni portugueses, ni siquiera el propio Alejandro VI, podian tener idea alguna de la implicancia a posteriori de estas donaciones sobre el Nuevo Mundo. Como afirma P. Castañeda Delgado, dicha ignorancia no afecta a la naturaleza de la concesión, ni a los fundamentos juridicos ${ }^{51}$ en que se basaron.

2) En segundo lugar, creo que es necesario tener siempre presente los cambios de época en las relaciones diplomáticas entre el papado y los diferentes príncipes cristianos después del Gran Cisma o Cisma de Aviñón (1378 y 1417). Asistimos durante todo el siglo XV a un importante esfuerzo diplomático por precisar los limites del poder papal frente a las aspiraciones de control de las Iglesias en cada uno de los reinos por parte de cada uno de los monarcas europeos. Esto se traducirá, como afirma J. M. Nieto Soria (1996) en una extraordinaria capacidad negociadora, en la que legados y nuncios, por un lado, y procuradores destacados en la Corte romana, por otro, ejercerán un papel decisivo ${ }^{52}$. El resultado, una capacidad de negociación

monarquia papal en la primera Edad Moderna, Akal, Madrid, 2010, p. 14. El autor, aun criticando la tesis de Ullmann, a la cual considera excesivamente simplista... al ver ello como un simple proceso degenerativo... (ibidem) entiende también que desde mediados del Quattrocento, los pontifices no se convirtieron solo en príncipes temporales, sino que, paulatinamente se fueron transformando en señores de un Estado italiano en vías de consolidación: dicha metamorfosis no se produjo sin que de ella derivaran algunas consecuencias más generales sobre el plano del State-building en el escenario europeo (ibid., p. 37).

50 La superioridad de la Iglesia sobre los príncipes estaba apoyada doctrinalmente a través del principio de que la humanidad tiende a constituir un cuerpo unitario compuesto por dos órdenes intimamente organizados de la vida (el espiritual y el temporal) que conforman la dualidad de la naturaleza humana. Cada uno, especializado en función de sus fines, siendo el primero el superior y eterno, y el segundo aquel que conduce lo temporal y terrenal. En este sentido, el conflicto aparece sintetizado en la propia relación de investiduras entre el poder de la Iglesia e Imperio, entendiéndola no como una dualidad de carácter definitivo e irresoluble, sino provisoria y temporal. Es que, para el pensamiento medieval, toda contradicción debe hallar su superación lógica, ya que la unidad precede y sucede a la pluralidad: principium unitatis. Como lo expresa Santo Tomás de Aquino (1225-T1274): [...] omnis multitudo derivatur ab uno... ab unum reducitur (toda la pluralidad deriva de uno y a uno se reduce) [Santo Tomás de Aquino ([1259] 2013) en Summa contra gentiles: Dios es, pues, fin de las cosas como algo que cada una ha de alcanzar a su manera... Dios es, a la vez, fin último de las cosas y primer agente (Libro III, cap. XVIII)]. O bien, Egidio Romano (1247-T 1316): [...] tota multitudi ab uno procedit [...] debe, necesariamente: [...] in unum aliquod reduci [...] (Egidio Romano (1292[1502]): De regimine principum, III, 2, c, 3). De esta manera -por extensión en la unidad- el término ecclesia puede ser utilizada extensivamente como imperio sobre la humanidad. Álvaro Pelayo (1280-T 1352) lo sintetiza brillantemente como: [...] unum corpus mysticum, una communitas et unus populus, una civilitas et politia Christiana [...]. Es decir, el principio unitario rige la concepción filosófico-politica medieval como orden natural del universo y las sociedades humanas encuentran así su metáfora comprensiva en una concepción organicista. Véase el trabajo de GIERKE, O. Von: Teorias politicas de la Edad Media..., op. cit.

51 CASTAÑEDA DELGADO, Paulino: La Teocracia..., op. cit., p. 348.

52 NIETO SORIA, José Manuel: "Enrique IV de Castilla y el Pontificado (1454-1474)", en La España Medieval, n. ${ }^{\circ}$ 19, 1996, pp. 167-238, cita en p. 169. 
diferencial con la Santa Sede de algunas de las monarquías continentales. Es el caso de Castilla y Portugal, y ello constituyó una herramienta fundamental a la hora de garantizar el apoyo del papado a sus empresas de expansión.

3) En tercer lugar, se puede afirmar que durante esta primera etapa de la expansión ultramarina, tanto para la monarquía portuguesa como para la castellana, el papado actúa como fons iuris cuya legitimidad se ve amparada en las fuentes doctrinales y jurídicas de la época -entre cuyos elementos se encontraba también la doctrina omninsular-, dando así reconocimiento a los nuevos descubrimientos insulares realizados por Colón y sosteniendo, para ello, una fórmula que ya estaba siendo impulsada por la propia cancillería castellana. La línea alejandrina, cuyo trazado definitivo aún no había sido negociado con Portugal, cuyo alcance nunca supuso el territorio americano; solo la posibilidad de seguir descubriendo islas más al oeste, y por lo tanto la donación incluye las formulaciones ya consagradas por las bulas anteriores de [...) no ser poseídas ya por príncipes cristianos ${ }^{53}$.

4) En cuarto lugar, que las Bulas Alejandrinas de partición no suponen -vistas en el conjunto sumario de las concesiones papales otorgadas durante el siglo XV- derechos diferenciales a los ya sostenidos por otros pontífices como Nicolás V, Calixto III y Sixto IV, para beneficiar a la Corona de Portugal y su expansión africana. Simplemente, es posible observar que en ellas es más marcado el carácter de bula de cruzada en función de la amenaza turca y el papel central del papado para el armado de las distintas estrategias y alianzas entre los príncipes cristianos. Como argumenta L. Weckmann, tampoco deben sorprendernos estas similitudes. En las prácticas de la época la cancillería papal -órgano altamente burocrático- retoma en la redacción de las diferentes bulas aquellas formulaciones ya trazadas y elaboradas, cimentadas en la tradición y el derecho, para su readecuación a las nuevas situaciones y necesidades de la politica del papado ${ }^{54}$.

5) En quinto lugar, tomadas en conjunto se evidencia que estas bulas configuran diferentes donaciones a los reinos de Portugal y de Castilla por parte de los distintos pontífices. El que ellas estén amparadas en la potestas omninsular (como sostiene L. Weckmann) o deriven de las prerrogativas del papa como vicario de Cristo (M. Maccarrone ${ }^{55}$ y P. Castañeda Delgado ${ }^{56}$ ), según las doctrinas hierocrática o teocrática, no cambia estrictamente la cuestión. No se puede olvidar que ambas formulaciones doctrinales de derecho gozaban hacia el siglo XV de validez jurídica. Ahora bien, tampoco es posible obviar que ambas sostienen también como fundamento central para la realización de dicha donación la obligación de evangelizar las tierras concedidas y, en términos jurídicos, este es el verdadero eje que sustenta la donación ${ }^{57}$.

53 WECKMANN MUÑOZ, Luis: Las Bulas Alejandrina..., op. cit., p. 529.

54 Ibid., p. 530.

55 MACCARRONE, Michele: Vicarius Christi. Storia del titulo papale, Lateranum, Roma, 1959.

56 CASTAÑEDA DELGADO, Paulino: La Teocracia..., op. cit.

57 Como sostiene ROJAS-DONAT, Luis: "El Papado bajomedieval...», art. cit., p. 70: La organización de la Iglesia indiana tuvo características especiales, cuyos fundamentos se encuentran 
6) En sexto lugar, llegados a este punto, creo que es importante tener presente también las limitaciones a las que estaba sujeto el propio papado. Ello determina en sí la posibilidad misma de dimensionar estas donaciones. Todas ellas se realizan por solicitud expresa de las propias Coronas de Portugal y Castilla: por lo tanto, su intervención es acordada por los actores. Como dijimos, son expresiones de la aceitada relación de negociación entre las cancillerias de ambos reinos y la curia romana. Por lo tanto, las soluciones negociadas no comienzan en Roma, terminan en ella. Este hecho ya habia sido advertido en su tiempo por R. Ortega López ${ }^{58}$ : hacia el siglo XV, el descubrimiento y la ocupación por un príncipe cristiano constituian título suficiente de adquisición de tierras y derechos sobre estos espacios ${ }^{59}$. A pesar de ello, el reconocimiento papal, sin ser eminentemente necesario, fue considerado conveniente en la época. Se constituye en elemento central de la politica exterior de sostenimiento de los derechos propios de cada Corona en la primera expansión atlántica sobre los nuevos territorios. Dicho reconocimiento fue deliberadamente buscado y afanosamente negociado por las distintas delegaciones diplomáticas de ambos reinos enviadas a Roma.

7) En séptimo lugar, tampoco podemos dejar de lado el hecho de que Roma, en estos momentos, actuaba como "caja de resonancia" de la política negociada entre las Coronas de Castilla y de Portugal en términos de la constitución de estos derechos. Las Bulas Alejandrinas de partición y la delimitación línea divisoria de espacios, fijada a cien (100) leguas al oeste de las islas Azores y Cabo Verde fueron asumidas por Portugal como una fórmula lesiva para sus propios intereses. Por ello Juan II de Portugal instruye al cardenal de Lisboa para encargarse directamente de las negociaciones con la Santa Sede y Castilla. El resultado, un acuerdo de partes, el Tratado de Tordesillas del 7 de junio de 1494, corriendo la línea divisoria a las trescientos setenta (370) leguas al oeste de Cabo Verde. Es decir, se trata de un acuerdo diplomático entre ambas Coronas, el cual se solicitó que fuese refrendado por la Santa Sede. La reafirmación tardó en llegar, no por oposición de algunas de las partes ni del papa, sino por un conjunto de contingencias que afectaron al papado: la muerte de Alejandro VI -aparentemente envenado-, el fallecimiento de su sucesor Pio III y, finalmente, la

en las bulas de Alejandro VI. En ellas los Reyes Católicos no se constituyeron en vicarios, pero si recibieron la exclusividad de la evangelización en las tierras descubiertas con la obligación de reclutamiento, envio y distribución de los misioneros. En las dos bulas Inter caetera (1493) estarán claramente delimitadas las obligaciones misionales que acompañan la donación. Se les otorgó derecho de patronato.

58 Véase estas problemáticas en DE LOURDES BEJARANO ALMADA, M: "Las Bulas Alejandrinas: Detonantes de la evangelización en el Nuevo Mundo", en Revista de El Colegio de San Luis, Nueva época, año VI, n. ${ }^{\circ} 12$, julio a diciembre, 2016, pp. 225-257.

59 Queda claramente expresado por HERRERA y TORDESILLAS, Antonio de: Historia General de los hechos de los castellanos en las Islas y tierra firme del mar Océano, Imprenta Real de Nicolás Rodríguez, Madrid, [1598] 1730, pp. 40-41: [...] por la posesión que de aquellas Nuevas Tierras habia tomado el Almirante, i por otras muchas causas, hubo grandes Letrados, que tuvieron opinión, que no era necesaria la confirmación, ni donación del Pontífice para poseer justamente aquel Nuevo Orbe; todavia los Reies católicos, como obedientisimos de la Santa Sede i piadosos Principes, mandaron al mismo Embaxador que suplicase a su Santidad fuese servido de mandar hacer gracia a la Corona de Castilla i de León de aquellas Tierras descubiertas, $i$ que se descubrieren adelante, $i$ expedir sus bulas acerca de ello [...]. 
elección de Julio II quien, recién iniciado el año 1506, confirma la partición acordada a través de la Bula Ea quae pro bono.

8) En octavo lugar, tampoco es posible abstraerse al pensamiento propio de la época y considerar solo una medida política de legitimación aquello que, en la práctica, se encontraba motorizado por una profunda convicción espiritual de los actores. Una buena ilustración de ello es la lectura del codicilo que continuó al testamento redactado por la reina Isabel de Casti$11 a^{60}$. Sus palabras son claras en este sentido: el Papa quien [...] nos fizo la dicha concession, de procurar inducir e traher los pueblos dellas e los convertir a nuestra santa fe católica [...]. Este nivel del problema no es superfluo, ya que queda claro que Isabel compone el dilema de los legítimos derechos castellanos sobre el Nuevo Mundo, no en los derechos generados por el descubrimiento y la ocupación, sino esencialmente en la donación papal; de allí el interés que ella tiene de trasladar en el codicilo la misión de continuar con la tarea de evangelización de estas nuevas tierras a sus sucesores.

9) Por último, ya entrados en el siglo XVI, todo el "escenario" observado anteriormente se verá absolutamente trastocado: el lugar de preeminencia del papado en el conjunto del orbe cristiano occidental ya deja de ser indiscutida, las corrientes subterráneas de la Reforma protestante harán estallar la antigua unidad espiritual medieval y los ya debilitados fundamentos del antiguo orden. Al mismo tiempo, con la expedición de Vasco Da Gama, Portugal alcanza la costa de Malabar (sudoeste de la India) el 20 de mayo de 1498, abriendo así la ansiada ruta maritima al comercio con el Oriente. Finalmente, para Castilla, y para los europeos en general, la ruta maritima abierta por Colón navegando hacia el oeste los enfrentaba a una nueva dimensión de pensar esos territorios desde una realidad continental llamada América.

\footnotetext{
60 Por quanto al tiempo que nos fueron concedidas por la Santa Sede Apostólica las islas e tierra firme del mar Océano, descubiertas e por descubrir, nuestra principal intención fue, al tiempo que lo suplicamos al papa Alejandro sexto [...] que nos fizo la dicha concession, de procurar inducir e traher los pueblos dellas e los convertir a nuestra santa fe católica, e enviar a las dichas islas e Tierra Firme del mar Océano prelados e religiosos e clérigos e otras personas doctas e temerosas de Dios, para instruir los vezinos e moradores dellas en la fe católica, e les enseñar e doctrinar buenas costumbres e poner en ello la diligencia debida, según como más largamente en las letras de la dicha concessión se contiene. Por ende suplico al rey, mi señor, mui afectuosamente, e encargo e mando a la dicha princesa mi hija e al dicho principe su marido, que ansi lo hagan e cumplan, e que este sea su principal fin, e que en ello pongan mucha diligencia, e non consientan e den lugar que los indios vezinos e moradores en las dichas Indias e Tierra Firme, ganadas e por ganar, reciban agravio alguno en sus personas e bienes; mas mando que sea bien e justamente tratados [...] (Cláusula XXI, Medina del Campo, 23 de noviembre de 1504).
} 


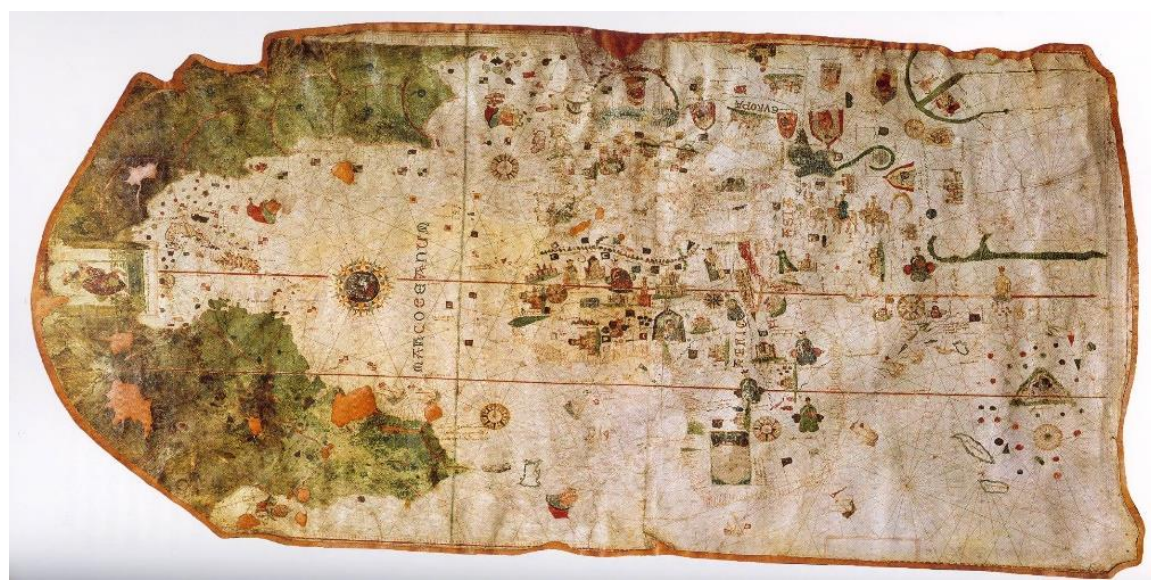

Imagen: mapa de Juan de la Cosa (1500) (Wikimedia Commons)

\section{Bibliografia}

ARRANZ MÁRQUEZ, Luis: Cristóbal Colón. Misterio y grandeza, Madrid, Marcial Pons, 2006.

BAYONA, Bernardo y ROCHE, Pedro: Sobre el poder del Imperio y del Papa, Biblioteca Nueva, Madrid, 2005.

BERTELLONI, Francisco: "Constitutum Constantini` y 'Romgedanke'. La donación constantiniana en el pensamiento de tres defensores del derecho imperial de Roma: Dante, Marsilio de Padua y Guillermo de Ockham" (2. ${ }^{\mathrm{a}}$ parte), Patrística et Mediaevalia, n. ${ }^{\circ} 4-5,1984$, pp. 67-99.

CASTAÑEDA DELGADO, Paulino: La Teocracia Pontifical en las controversias sobre el Nuevo Mundo, Universidad Nacional de México, México, Serie C, Estudios Históricos, n. ${ }^{\circ}$ 59, 1996.

COLÓN, Cristóbal: Cristóbal Colón, Textos y documentos completos. Relaciones de viajes, cartas y memoriales, edición a cargo de Consuelo Varela, Alianza editorial, Madrid, 1982.

DE LOURDES BEJARANO ALMADA, M.: "Las Bulas Alejandrinas: Detonantes de la evangelización en el Nuevo Mundo", en Revista de El Colegio de San Luis, Nueva época, año VI, n. ${ }^{\circ} 12$, julio a diciembre, 2016, pp. 225-257.

DUVE, Thomas: "El tratado de Tordesillas: ‘¿Una revolución espacial?’ Cosmografia, prácticas jurídicas e Historia del Derecho Internacional Público", en Revista de Historia del Derecho, n. ${ }^{\circ}$ 54, Instituto de Investigaciones de Historia del Derecho-Buenos Aires, julio-diciembre, 2017, pp. 77-107.

EGIDIO ROMANO ([1292]1502): De regimine Principium. [http://uvadoc.uva.es / handle/10324/1586].

FRIED, Johannes: "Donation of Constantine" and "Constitutum Constantini", The Misinterpretation of a Fiction and its Original Meaning. Millennium Studies in the Culture and History of the First Millennnium, C. E., 3, Berlin-New York, Walter de Gruyter, 2007.

GIERKE, O. Von: Teorias politicas de la Edad Media, Centro de Estudios Constitucionales, Madrid, 1995.

HERA, Alberto de la: "El regio patronato de Granada y las Canarias", en Anuario de Historia del Derecho Español, Tomo LXXXVII, 1957-58, pp. 5-16. 
HERRERA y TORDESILLAS, Antonio de: Historia General de los hechos de los castellanos en las Islas y tierra firme del mar Océano, Imprenta Real de Nicolás Rodríguez, Madrid, [1598] 1730.

KANTOROWICZ, Ernst: Los dos cuerpos del rey. Un estudio de teología politica medieval, Akal, Madrid, 2018 (reedición).

MARTINS DA SILVA MARQUES, João: Descobrimentos portugueses. Documentos para a sua historia, Instituto de Alta Cultura, Lisboa, 1944, vol. I (1415-1460).

MARTÍNEZ LLORENTE, Félix: "El escudo de armas de Cristóbal Colón: estudio de un acrecentamiento heráldico", en Cristóbal Colón y el Descubrimiento del Nuevo Mundo. Actas del Congreso Internacional. V Centenario de la muerte del Almirante. Valladolid, 15 a 19 de mayo de 2006, Ayuntamiento de Valladolid, Valladolid, 2006, dos tomos, texto citado, tomo I, pp. 233268.

NIETO SORIA, José Manuel: "Enrique IV de Castilla y el Pontificado (14541474)", en La España Medieval, n. ${ }^{\circ} 19,1996$, pp. 167-238.

POLO, Marco: Libro de las Maravillas, Anaya, Madrid, [1317] 1984.

PRODI, Paolo: El Soberano Pontifice. Un cuerpo y dos almas: la monarquía papal en la primera Edad Moderna, Akal, Madrid, 2010.

REMESEIRO FERNÁNDEZ, Alejandro: Bula Inter Caetera de Alejandro VI (1493) y las consecuencias politico-administrativas del descubrimiento de América por parte de Colón en 1492, Galeatus, Madrid, 2004.

ROJAS-DONAT, Luis: "El Papado bajomedieval, dueño de todas las islas. A 70 años de la teoría omni-insular de Luis Weckmann", en Teología y Vida, n. ${ }^{\circ}$ 61, 2020, pp. 47-72.

RUMEU DE ARMAS, Antonio: "Colección de Bulas y Letras expedidas por los pontífices Benedicto XIII, Martín V, Eugenio IV y Nicolás V, promoviendo la primera cristianización de las Islas Canarias. La Diócesis del Rubicón", en Anuario de Estudios Atlánticos, n. ${ }^{\circ}$ 52, 2006, pp. 109-134.

SABINE, George H.: Historia de la teoría politica, Fondo de Cultura Económica, México, [1937] reedición de 1996.

SÁNCHEZ GONZÁLEZ, Antonio: "El blasón heráldico de Colón", en VV. AA.: La heráldica en los descubrimientos y Cristóbal Colón, Sociedad Andaluza de Educación Matemática Thales, Academia Iberoamericana de La Rábida, 2013, pp. 81-92.

SANTO TOMÁS DE AQUINO: Summa contra gentiles, [1259] edición electrónica 2013, [<http://santotomasdeaquino.verboencarnado.net/libro-iiidios-fin-ultimo-ygobernador-supremo/>].

SANTO TOMÁS DE AQUINO: Suma de Teología, Biblioteca de autores cristianos, Madrid, edición electrónica [1274] 1989 [https://sumateologica.files. wordpress.com/2009/09/sumadeteologia2.pdf.].

SUÁREZ FERNÁNDEZ, Luis: "Estudio Introductorio", en Tratado de Tordesillas, Ministerio de Educación y Ciencia. Dirección de Archivos y Bibliotecas, Madrid, 2007. 
ULMANN, Walter: A short history of the papacy in the Middle Ages, Methuen and Co. Ltd., Londres, 1972.

URIBE RUEDA, Álvaro: Bizancio, el dique iluminado, ediciones LAVP, New York, 2019.

VALLA, Lorenzo: Refutación de la Donación de Constantino, Clásicos Latinos Medievales y Renacentistas, n. ${ }^{\circ}$ 27, Edición de Antoni Biosca y Francisco Sevillano, Akal, Madrid, 2011.

WECKMANN Muñoz, Luis: Las Bulas Alejandrinas de 1493 y la teoría politica del papado medieval. Estudio de la supremacía papal sobre las islas, 10911493, Universidad Nacional Autónoma de México, Publicaciones del Instituto de Historia, México, 1949.

WECKMANN MUÑOZ, Luis: La herencia medieval de México, Fondo de Cultura Económica, México, segunda edición revisada, 1994. 